\title{
ВЛИЯНИЕ ФРАКЦИОННОГО СОСТАВА ПЕКОВ НА ТЕРМИЧЕСКУЮ УСТОИЧИВОСТЬ ПОЛИКАПРОАМИДА
}

При использовании пеков в качестве модифицирующей добавки к поликапроамиду (ПКА) решающее значение имеют их структурно-механические и физико-химические свойства, которые в значительной степени зависят от источника сырья для получения пеков. Химический состав и свойства пеков могут колебаться в широких пределах, поскольку различны как природа исходного сырья (тип нефти, каменного угля), так и условия технологических процессов, приводящих к образованию пеков.

В исследовательской и технологической практике стало общепринятым следующее разделение пеков на фракции, отличающиеся по растворимости [']: нейтральные смолы или мальтены, растворимые в легком бензине, пентене, гексане ( $\gamma$-фракция); асфальтены, нерастворимые в петролейном эфире, но растворимые в горячем бензоле, толуоле ( $\beta$-фракция); карбены, частично растворимые в пиридине, хинолине ( $\alpha_{2}$-фракция); карбоиды, практически ни в чем не растворимые $\left(\alpha_{1}\right.$-фракция). В результате термических превращений одна фракция переходит в другую, что сопровождается ростом молекулярной массы, отношения $\mathrm{C} / \mathrm{H}$ и ароматичности.

В реальных пековых продуктах все указанные фракции существуют и в принципе мало отличаются друг от друга по строению фрагментов, однако асфальтены ( $\beta$-фракция) являются наиболее представительной частью системы и поэтому они, сохраняя пластичность, растворимость и имея уже высокие молекулярные массы, в основном определяют физикохимические характеристики пека. Кроме того, асфальтены оказывают сильнсе влияние на вязкость связующего, поскольку бо́льшая часть функциональных групп связующего - фенольных и карбонильных находится именно в этой фракции [ㄹ.

Различия между пеками по химическому составу, ароматичности и другим показателям влияют на их термическую стабильность и термостабилизирующую способность. В свою очередь можно предположить, что структура и физико-механические свойства модифицированных нитей ПҚА-пек во многом будут определяться характеристикой фракционного состава пека, содержащегося в полимере.

В данной статье представлены результаты исследования влияния фракционного состава пеков на термические свойства модифицированных ПКА нитей. Использовали нефтяные пеки, приготовленные из асфальта кубового остатка нефти.

Подготовку пеков осуществляли путем длительного нагревания асфальта в инертной атмосфере с постепенным повышением температуры. Характеристики применяемых пеков представлены в табл. 1.

Как следует из представленных данных, все исследуемые пеки заметно отличаются по фракционному составу. Было установлено также, что эти пеки обладают способностью к волокнообразованию.

Объектом исследования явились волокна, сформованные из смесн ПКА и $30 \%$ каждого в отдельности из представленных в таблице пеков, приготовленной экструзионным смешением компонентов в расплаве. 
Характеристика фракционного состава нефтяных пеков

\begin{tabular}{|c|c|c|c|c|}
\hline \multirow[b]{2}{*}{ Образец } & \multirow{2}{*}{$\begin{array}{c}\text { Температура } \\
\text { размягчения, } \\
{ }^{\circ} \mathrm{C}\end{array}$} & \multicolumn{3}{|c|}{ Содержание фракций, \% } \\
\hline & & $\gamma$ & $\beta$ & $\alpha_{1}+\alpha_{2}$ \\
\hline Пек № 44 & $215-220$ & 8,7 & 89,1 & 2,2 \\
\hline „ № 45 & $190-195$ & 24,0 & 75,0 & до 1 \\
\hline " № 84 & 190 & 25,7 & 74,0 & 0,3 \\
\hline " № 47 & 166 & 33,0 & 66,0 & до 1 \\
\hline " № 35 & $195-200$ & 28,3 & 50,7 & 21,0 \\
\hline , № 38 & $220-225$ & 22,0 & 45,0 & 33,0 \\
\hline
\end{tabular}

На примере ПКА волокон, модифицированных пеками № 38 и № 45 как наиболее различающимися по фракциям, определены их термические свойства в зависимости от фракционного состава вводимых пеков. Термическую устойчивость модифицированных волокон исследовали методом дифференциально-термического анализа (ДТА) и термогравиметрического анализа в области температур $20-600^{\circ} \mathrm{C}$ при скорости нагрева от 3 до $10 \%$ мин. Данные представлены в табл. 2.

Таблица 2

Влияние фракционного состава пека на термическую устойчивость модифицированных поликапроамидных волокон при нагревании до $600{ }^{\circ} \mathrm{C}$ (скорость нагрева $10^{\circ} /$ мин)

\begin{tabular}{c|c|c|c}
\hline Образец & $\begin{array}{c}\text { Температура } \\
\text { интенсивной } \\
\text { деструкции, } \\
{ }^{\circ} \mathrm{C}\end{array}$ & $\begin{array}{c}\text { Максимальная } \\
\text { скорость потери } \\
\text { массы, } \\
\% / \text { мин }\end{array}$ & $\begin{array}{c}\text { Суммарная потеря, } \\
\text { массы, \% }\end{array}$ \\
\hline ПКА-пек № 38 & 360 & 6,7 & 100,0 \\
ПКА-пек № 45 & 410 & 7,2 & 91,0
\end{tabular}

ПКА волокно, модифицированное пеком № 45, отличается большей термоустойчивостью, о чем свидетельствуют сохранение массы образца при нагревании до $600^{\circ} \mathrm{C}$ и скорость потери массы. Это, по-видимому, обусловлено тем, что пек № 45 характеризуется повышенным содержанием асфальтенов ( $\beta$-фракции), которые, как уже указывалось выше, являются определяющими в оценке их физикофхимических свойств.

Дополнительная информация о влиянии фракционного состава на термораспад модифицированных пеками ПКА волокон была получена методом ступенчатой пиролизной газовой хроматографии (СПГХ), который позволяет не только определять температурный интервал термораспада волокон, но и идентифицировать выделяющиеся летучие продукты [3]. Работу проводили на газовом хроматографе «Хром 5», снабженном блоком пиролиза. Летучие продукты разделяли на двух колонках. Пиролиз пробы (2 мг) проводили в течение $12-15$ с при температурах от 300 до $700^{\circ} \mathrm{C}$. Результаты этих исследований приведены в табл. 3. Они подтверждают данные ДТА о большей термоустойчивости волокон, модифицированных пеком № 45, по сравнению с волокнами, модифицированными пеком № 38 .

Для обоснования этого факта было проведено фракционирование пека № 35, близкого по составу к пеку № 38. Метод фракционирования основан на принципе селективного растворения отдельных углеводородов в различных растворителях. В качестве растворителей использовали гексан и толуол. 
Выход летучих проду̇ктов при пиролизе модифицированных пеками поликапроамидных волокон

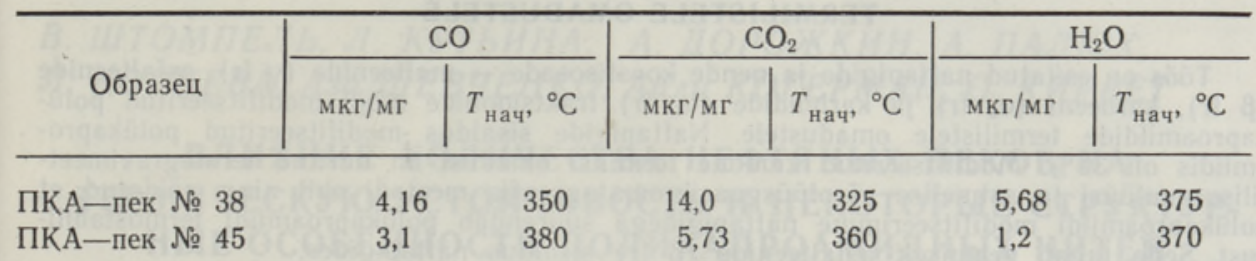

Путем дробного растворения выделили три фракции пека $(\gamma, \beta$ и $\alpha)$. После растворения в гексане отделилась $\gamma_{-}$фракция. Остаток после растворения в гексане составляли $(\alpha+\beta)$-фракции. После растворения в толуоле отделилась $\alpha$-фракция от $\beta$-фракции. Тщательно высушенные $\alpha$ - и $\beta$-фракции добавляли в ПКА в качестве модификаторов и на основе этих смесей формовали волокна. О термостойкости исследуемых образцов, модифицированных отдельными фракциями пека, судили по выделению мономера ( $\varepsilon$-капролактама) при термораспаде ПКА волокон, используя СПГХ [3].

На рисунке приведены температурные зависимости выхода $\varepsilon$-капролактама при ступенчатом пиролизе в интервале температур от 300 до $550^{\circ} \mathrm{C}$. Эти данные указывают на то, что $\beta$-фракция несколько снижает выход $\varepsilon$-капролактама при пиролизе, что в какой-то мере подтверждает положение о доминирующей роли $\beta$-фракции в пеке, как при оценке свойств пека в целом, так и при оценке полимерных смесей и волокон, его содержащих.

Температурная зависимость выхода $\varepsilon$-капролактама: 1 - ПКА-пек № $35 \quad(20 \%$ мас.), $2-$ ПКА- $\alpha$-фракщия (5\% мас.), $3-$ ПКА- $\beta$-фракция ( $15 \%$ мас.).

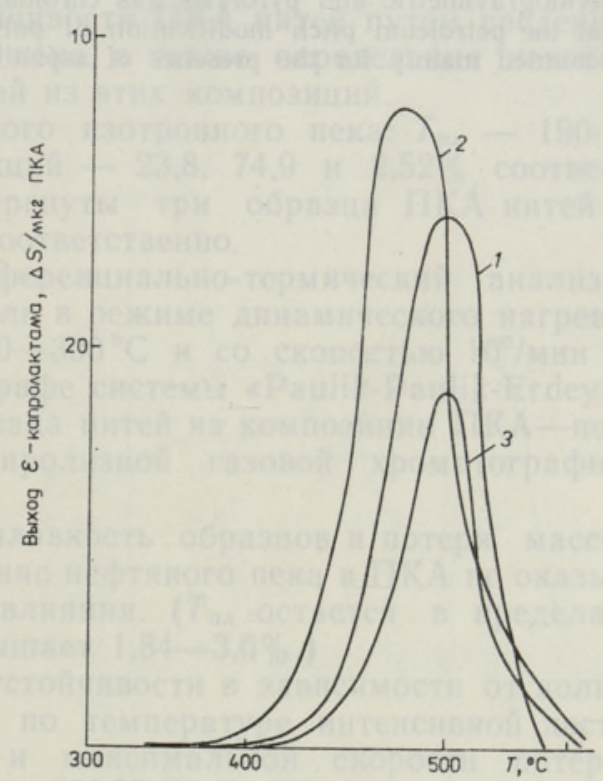

Сопоставляя полученные данные, можно полагать, что пеки, входящие в состав волокна из смеси ПКА-пек и содержащие большое количество $\beta$-фракции, улучшают их термические свойства.

\section{Л И ТЕ Р А Т У А}

1. Привалов В. Е., Степаненко М. А. Каменноугольный пек. М., 1981.

2. Фиалков А. С. Углеграфитовые материалы. М., 1979, 58.

3. Когерман $A$. Пиролизная газовая хроматография в исследовании термических свойств полимеров // Изв. АН ЭССР. Хим., 1984, 33, № 4, 235-243.

\section{Киевский филиал вНнив}

Ннститут химии

Академии наук Эстонской ССР
Поступила в редакцию 29/V 1989 
L. KUTINA, A. DOROŻKIN, Hilja TAAL, Aili KOGERMAN, Olga ONDA,

T. BELITSEENKO, G. BERG, V. STOMPEL, O. KIRRET

\section{PIGIDE FRAKTSIOONKCOSSEISU MÕJU POLOKAPROAMIIDI TERMILISTELE OMADUSTELE}

Töös on esitatud naftapigide ja nende koostisosade - malteenide $(\gamma \mathrm{fr})$, asfalteenide ( $\beta$ fr), karbeeni ( $\alpha_{2}$ fr) ja karboidide $\left(\alpha_{1}\right.$ fr) fraktsioonide mõju modifitseeritud polükaproamiidide termilistele omadustele. Naftapigide sisaldus modifitseeritud polükaproamiidis oli $30 \%$. Modifitseeritud kiudude termilisi omadusi on uuritud termogravimeetrilise analüüsi $\mathrm{ja}$ astmelise pürolüüsgaasikromatograafia meetodi abil ning năidatud, et polükaproamiidi modifitseerimine naftapigidega suurendab polükaproamiidi termostabiilsust. Seda tagab peamiselt asfalteenide $(\beta$ fr) sisaldus naftapigides.

L. KUTYINA, A. DOROZHKIN, Hilja TAAL, Aili KOGERMAN, Olga ONDA, T. BELITCHENKO, G. BERG, V. SHTOMPEL, O. KIRRET

\section{EFFECT OF THE PITCH FRACTIONAL COMPOSITION ON THE THERMAL PROPERTIES OF POLYCAPROAMIDE}

In the present work the effect of petroleum pitch and its components - malthenes ( $\gamma \mathrm{fr}$ ), asphaltenes ( $\beta \mathrm{fr}$ ), carbenes ( $\alpha_{2} \mathrm{fr}$ ) and carboids $\left(\alpha_{1} \mathrm{fr}\right)$ on the thermal properties of modified polycaproamides was investigated. The petroleum pitch content of modified polycaproamide was $30 \%$. Thermal properties of modified fibres were studied using thermogravimetric and pyrolysis gas chromatographic methods of analysis. It is shown that the petroleum pitch modification of polycaproamide enhances its thermal stability, accounted mainly for the presence of asphalthenes $(\beta \mathrm{fr})$ in petroleum pitch. 